\title{
COYOTE AND MAGPIE BEHAVIOUR AT WHITE-TAILED DEER CARCASSES
}

TIM BRACE, Group Site 308, Box 49, R.R. \# 3, Saskatoon, Saskatchewan. S7K $3 J 6$

My mother and I shot two Whitetailed Deer near our Pike Lake, Saskatchewan, home during the 1992 deer season. After processing the deer, the remnants (heads, skeletons and some meat) were deposited about 200 yards south of our house on 20 December.

Magpies found and scavenged the carcass on 21 December. Coyotes were not observed until 24 December, at which time four of them appeared.

Some intraspecies exclusion occurred, as only one coyote visited either carcass at any one time. The other coyotes remained about 20 yards away. After about half an hour, the two coyotes that had alternately scavenged the deer plus one of the two observer coyotes departed. The fourth animal then approached and ate the frozen meat for about 20 minutes before departing in the same direction as the others.

On 28 December, a single coyote was observed at one carcass (the other carcass had been removed by this time). Twelve magpies were also present; however, the coyote excluded the magpies from the carcass. The magpies attempted to approach the carcass on many occa- sions, but the coyote chased them about 10 yards whenever a bird approached. Uninterrupted feeding by the coyote lasted less than one minute. When chased, the magpies would scatter ahead of the mammal, which occasionally leaped several feet into the air after a bird. The coyote failed to capture any magpies. The coyote fed on the deer until about 12:30 p.m., when a car approached our house, and the coyote left. The magpies resumed feeding after the coyote's departure.

On 31 December, a single coyote ran towards and then chewed on the frozen carcass. It was first observed at 11:28 a.m. and it departed at 12:51 p.m. The temperature at this time was $-43^{\circ} \mathrm{C}$. It departed in a direction differing from than of its approach. At that time there were no magpies in the vicinity of the deer carcass.

At 2:30 p.m., 31 December, an additional 20 pounds of venison and antelope meat were put at the location formerly occupied by the deer carcasses. Although tracks indicated that this meat was removed by coyotes during the evening of 31 December, the actual removal was not observed. 